\title{
Cortisol, alpha amylase, blood pressure and heart rate responses to food intake in men aged $50-70$ years: importance of adiposity
}

\author{
Sisitha U Jayasinghe ${ }^{1}$, Susan J Torres ${ }^{1}$, Caryl A Nowson ${ }^{1}$, Alan J Tilbrook ${ }^{2}$ and Anne I Turner ${ }^{\text {* }}$
}

\begin{abstract}
Background: Increased adiposity is often associated with over activation of the hypothalamo-pituitary adrenal axis (HPA axis) and the sympatho-adrenal medullary system (SAM system) and excessive activation of these pathways in response to physiological challenges may be linked with the development of diseases. We tested the hypothesis that overweight/obese men aged 50-70 years will have greater HPA axis and SAM system responses to food intake compared with age matched lean men.

Lean (Body Mass Index; BMI = 20-25 kg/m²; $\mathrm{n}=19)$ and overweight/obese (BMl $\left.=27-35 \mathrm{~kg} / \mathrm{m}^{2} ; \mathrm{n}=17\right)$ men (50-70 years) made their own lunch using standardised ingredients at $1200 \mathrm{~h}$. Concentrations of cortisol and alpha amylase were measured in saliva samples collected every 15 min from 1145 h-1400 h with the exception of during lunch (1215 h) where no sample was collected. Blood pressures and heart rate were measured at $1145 \mathrm{~h}$ and every 15 minutes between $1245 \mathrm{~h}$ and $1400 \mathrm{~h}$.

Results: Overweight/obese men had significantly higher body weight, BMl, percentage body fat and waist and hip circumferences compared to lean men ( $p<0.001$ for all). The meal consumed by the participants consisted of 22\% protein, $53 \%$ carbohydrates and $25 \%$ fat. Overweight/obese men responded to lunch with a significant increase in cortisol whereas lean men did not show such an increase (time*treatment $p=0.008$ ). There were no significant differences between the groups in the salivary alpha amylase response to the meal (time*treatment $p=0.195$ ) or in SBP, DBP, MAP or HR responses (time*treatment $p=0.726,0.898,0.713,0.620$, respectively).

Conclusions: While men with a moderate level of overweight/obesity had a significant HPA axis response (as measured by salivary cortisol) to a standardised lunch, lean men had no HPA axis response. Lean and overweight/obese men had similar increases in SAM system activity (as measured by salivary alpha amylase) in response to the meal.
\end{abstract}

Keywords: Food intake, SAM system, HPA axis, Obesity, Adiposity, Men's health, Cortisol

\section{Background}

Exposure to stress activates the SAM system (which results in increases in salivary alpha amylase, blood pressure and heart rate) and the HPA axis (which results in increases in salivary cortisol) [1]. Hyperactivity of these pathways can be associated with the development of numerous chronic conditions including cardiovascular disease, type 2 diabetes, anxiety and depression [2]. Obesity is a worldwide epidemic and is associated with numerous health complications and increased morbidity [3].

\footnotetext{
* Correspondence: anne.turner@deakin.edu.au

${ }^{1}$ Centre for Physical Activity and Nutrition Research, School of Exercise and Nutrition Sciences, Deakin University, Burwood VIC 3125, Australia Full list of author information is available at the end of the article
}

Animal studies by our research group as well as others suggest that obesity can be associated with increased HPA axis and SAM system responses to stress [4,5]. Evidence from human studies is not conclusive in this regard. Some studies have suggested hyperactivity of the stress pathways in obesity in response to various stressors such as postural challenges, video game challenges, exposure to cold, mental arithmetic challenges and pharmacological stimulation [6-8]. Others have suggested that there is no association between increased adiposity and stress pathway activation or that increased adiposity is associated with lower stress pathway activation to similar stressors [9-11].

Ciomed Central

the

(c) 2014 Jayasinghe et al.; licensee BioMed Central Ltd. This is an Open Access article distributed under the terms of the Creative Commons Attribution License (http://creativecommons.org/licenses/by/4.0), which permits unrestricted use, distribution, and reproduction in any medium, provided the original work is properly credited. The Creative Commons Public Domain Dedication waiver (http://creativecommons.org/publicdomain/zero/1.0/) applies to the data made available in this article, unless otherwise stated. 
Food intake is a physiological challenge that can activate the HPA axis [12-14]. Gibson and colleagues reported that a high protein (32\% of energy in protein) mid-day meal can elicit greater (1.5 -2 fold increase) HPA axis responses compared with a low protein $(5 \%$ of energy in protein) mid-day meal in young healthy females [12]. They also showed that a high protein meal (39\% energy in protein) can elicit a significant HPA axis response in young men [12]. Nevertheless, Martens and colleagues measured cortisol responses in men to three different types of shakes (high protein shake, high carbohydrate shake and high fat shake) and reported that only the high carbohydrate shake resulted in an increase in cortisol secretion [14]. Each of the shakes used contained $2306 \pm 77 \mathrm{~kJ}$. Furthermore, Vicennati and colleagues reported that only high carbohydrate meals $(89 \%$ carbohydrate, $11 \%$ protein, $0 \%$ fat) but not high protein/ fat meals (53\% lipids, $43 \%$ protein and $4 \%$ carbohydrate) resulted in a significant HPA axis response in women who predominantly had a visceral body fat distribution compared with women with peripheral body fat distribution and normal weight healthy controls [13]. Therefore, it appears that the evidence in humans in this area is inconclusive. None of the past studies in this area have considered the activation of the SAM system responsiveness to ingestion of food. Thus, there is a paucity of evidence on SAM system reactivity to consumption of food. Furthermore, no previous studies have investigated the effects of adiposity on HPA axis and SAM system activity in lean and overweight/obese men in response to food intake. Since food intake is a challenge experienced by the human body several times per day, a greater understanding of the influence of adiposity on the physiological response to food intake is of fundamental importance. If overweight/obese men have a greater activation of the stress pathways every time they consume food it is plausible that they may be more susceptible to the development of stress-related diseases.

Research shows that, during challenges, activation of the SAM system increases the secretion of alpha amylase by the salivary glands [15-18]. Simple sampling procedures of saliva makes salivary alpha amylase a useful non-invasive measure of SAM system activity [19]. Further advantages of salivary alpha amylase include its concentration being independent of the salivary flow rate [18].

Activation of the HPA axis by stress results in the sequential secretion of corticotrophin releasing hormone (CRH) and arginine vasopressin (AVP) from the hypothalamus, adrenocorticotrophic hormone (ACTH) from the anterior pituitary gland and glucocorticoids such as cortisol from the adrenal cortex $[20,21]$. Changes in the above parameters are used as markers of the activity of these stress pathways.

The aim of this investigation was to identify differences between lean and overweight/obese men in HPA axis responses (measured via salivary cortisol) and SAM system responses (measured via salivary alpha amylase) to the consumption of a standardised lunch. It was hypothesised that overweight/obese men will have greater salivary cortisol and salivary alpha amylase responses to the standardised lunch compared with lean men.

\section{Methods}

\section{Participants}

Men aged 50-70 years were recruited using newspaper and online advertisements, fliers in community centres and Medical Clinics, mail outs to participants of previous studies and by fliers dropped in mail boxes. Exclusion criteria were prior diagnosis with Cushing's syndrome, any stress or anxiety disorder, depression, diseases of the adrenal gland, type 2 diabetes, heart disease (including use of a pacemaker), high cholesterol, stroke, cancer or use of blood pressure or diabetes medication. Men were also excluded if their BMI fell outside of the required ranges $\left(20-25 \mathrm{~kg} / \mathrm{m}^{2}\right.$ for lean and $27-35 \mathrm{~kg} / \mathrm{m}^{2}$ for overweight/ obese), if their resting blood pressure exceeded $160 \mathrm{mmHg}$ for systolic blood pressure or $90 \mathrm{mmHg}$ for diastolic blood pressure.

Written informed consent was provided by all men prior to participation in the study. All procedures were approved by the Human Research Ethics Committee of Deakin University (Project code: EC00213) and conformed to the guidelines of the National Health and Medical Research Council's National Statement on Ethical Conduct in Human Research (2007).

\section{Experimental procedure}

Participants were asked to abstain from smoking, ingesting any caffeine containing beverages (e.g. tea, coffee, cola), liquorice, alcohol or drugs (except for any regular medications) and from strenuous physical activity during the 12 hours prior to participation in the study. They were asked to arrive at the laboratory at $1100 \mathrm{~h}$ and they were given a standardised lunch at $1200 \mathrm{~h}$. The first saliva sample was collected at $1145 \mathrm{~h}$, the second one at $1200 \mathrm{~h}$ (immediately before lunch), third at $1230 \mathrm{~h}$ and subsequent samples were collected every 15 minutes until $1400 \mathrm{~h}$. Systolic blood pressure (SBP), diastolic blood pressure (DBP), mean arterial pressure (MAP) and heart rate $(\mathrm{HR})$ were measured using a clinical blood pressure monitor (Criticare systems Inc, Wisconsin, USA) at $1145 \mathrm{~h}, 1245 \mathrm{~h}$ and every 15 minutes from there onwards until $1400 \mathrm{~h}$. Participants were allowed a break to use the bathroom immediately after the $1330 \mathrm{~h}$ saliva and blood pressure/heart rate sampling.

\section{Anthropometric measures}

Participant's height (Measurement Concepts, North Bend, Australia), body weight (TANITA, Wedderburn, Melbourne, 
Australia) and percentage body fat using bio electrical impedance (TANITA, Wedderburn, Melbourne, Australia) were measured at the start of the experimental day. Body mass index (BMI) was calculated using the equation $\mathrm{BMI}=$ body mass $(\mathrm{kg}) /$ height $(\mathrm{m})^{2}$. Waist circumference was measured at the midpoint between the last rib and the anterior superior iliac spine using a tape measure and hip circumference was measured at the widest point of the gluteal area [22]. Waist to hip ratio was calculated by dividing waist circumference by hip circumference.

\section{Test meal}

The test meal consisted of lunch made by the participants from a choice of standardised ingredients including bread, margarine, processed meat (ham or chicken), tomato, cucumber, cheese, nuts, fruit bars and a fruit drink (juice box). Water was available ad libitum. Records were collected of foods and quantities consumed in household measures. Foods consumed were entered into and analysed using FoodWorks software (Xyris, Queensland, Australia).

\section{Saliva sampling}

Salivette sampling tubes (Sarstedt, Ingle Farm, Australia) were used for sample collection. These tubes consist of a centrifugation tube and a cotton swab. Participants were instructed to hold the cotton swab in their mouth for 2 minutes. They were asked to put the cotton swab under their tongue for the first 30-45 seconds and to move it around the oral cavity for the remainder of the duration without chewing it or holding it between their teeth. Temporary storage of samples on ice occurred immediately after collection and samples were centrifuged at $2000 \mathrm{rpm}$ for 5 minutes at $4^{\circ} \mathrm{C}$ after the testing period. Resultant saliva was stored at $-80^{\circ} \mathrm{C}$ until assayed. Since the measurement of saliva cortisol has been shown to be unaffected by blood contamination due to micro-injury of the oral cavity [23], we did not perform haemoglobin assays in saliva to check for blood contamination. This approach is in accordance with previous research [12,24] that has considered salivary cortisol concentrations in response to food intake.

\section{Saliva cortisol assays}

Saliva concentrations of cortisol were measured using an enzyme immunoassay (Diagnostic Systems Laboratories, TX, USA). All samples from a single participant were assayed within the same assay. Thirty-one assays were conducted with a mean sensitivity of $0.035 \mu \mathrm{g} / \mathrm{dL}$. The intra-assay coefficient of variation was $6.9 \%$ at $0.25 \mu \mathrm{g} /$ $\mathrm{dL}$ and $8.2 \%$ at $2.0 \mu \mathrm{g} / \mathrm{dL}$. The inter-assay coefficient of variation was $9.4 \%$ at $0.28 \mu \mathrm{g} / \mathrm{dL}$ and $7.7 \%$ at $1.8 \mu \mathrm{g} / \mathrm{dL}$.

\section{Salivary alpha amylase assays}

Saliva concentrations of alpha amylase were measured using a kinetic assay kit (Salimetrics, PA, USA). All samples from a single participant were assayed within the same assay. Thirty-six assays were conducted with a mean sensitivity of $0.4 \mathrm{U} / \mathrm{ml}$. The intra-assay coefficient of variation was $7.4 \%$ at $156.3 \pm 4.1 \mathrm{U} / \mathrm{ml}$. The interassay coefficient of variation was $7.4 \%$ at $20.7 \mathrm{U} / \mathrm{ml}$ and $7.0 \%$ at $257.3 \mathrm{U} / \mathrm{ml}$.

\section{Statistical analysis \\ Preliminary analysis}

Pre- treatment salivary cortisol and pre-treatment salivary alpha amylase were defined as the concentrations of the hormones in the samples collected at $1200 \mathrm{~h}$. Pretreatment SBP, DBP, MAP and HR were defined as the value recorded at $1145 \mathrm{~h}$. Peak height for cortisol was defined as the highest value obtained for each individual between 1230 h- 1400 h, inclusive. Since the SAM system appears to have had a secondary activation at the time of the break to use the bathroom, peak height for salivary alpha amylase was defined as the highest value obtained from 1230 h-1330 h. Peak height for all cardiovascular parameters was defined as the highest value obtained between 1245 h-1330 h. Reactivity was calculated by subtracting the pre-treatment value from the peak height for all parameters. Area under the curve (AUC) with respect to increase was calculated for cortisol using values between $1200 \mathrm{~h}-1400 \mathrm{~h}$, for salivary alpha amylase using values between $1200 \mathrm{~h}-1330 \mathrm{~h}$ and for SBP, DBP, MAP and HR using values between $1145 \mathrm{~h}-1330 \mathrm{~h}$ after the subtraction of the pre-treatment value from each data point. AUC for all parameters were calculated using the trapezoid rule utilising Sigmaplot graphing software (Systat Software Inc., California, USA).

\section{Analysis}

Data were analysed using the Statistical Package for the Social Sciences software version 21.0 for windows (SPSS. Inc, Chicago, USA). Kolmogorov-Smirnov and Shapiro Wilk tests were conducted to test for normality. Tests for homogeneity of variance were conducted using Levene's test of equality of error variances. Descriptive characteristics were compared between groups using univariate analysis of variance. Salivary cortisol, salivary alpha amylase, blood pressures and heart rate were compared within and between subjects using repeated measures analysis of variance. The within subjects factor was time and the between subjects factor was treatment. When the time effect for salivary cortisol was considered separately in each group, only data from $1200 \mathrm{~h}-1400 \mathrm{~h}$ were included. Derived salivary cortisol, salivary alpha amylase and cardiovascular parameters (pre- treatment, peak height, reactivity and area under the curve) were 
compared between groups using univariate analysis of variance. $\mathrm{P}<0.05$ was considered statistically significant.

\section{Results}

\section{Participants}

Data were collected from 24 lean and 22 overweight/ obese men who were eligible for the study. Two lean and 5 overweight/obese were subsequently excluded from the analyses due to insufficient saliva volume to undertake the assays for cortisol and alpha amylase. It was ascertained in initial analyses that the lean group was significantly ( $\mathrm{p}=0.054)$ older $(64.2 \pm 1.1$ years $)$ than the overweight/ obese group (61.1 \pm 1.1 years). To remove this effect (to ensure that men were age matched by group), the results of the three oldest lean men were excluded from the final analyses. Consequently, 19 lean and 17 overweight/obese were included in the final study cohort. The men that were excluded did not differ significantly from the final cohort in any of the baseline characteristics.

\section{Participant characteristics}

Overweight/obese men had significantly higher body weight, BMI, percentage body fat and significantly lower percentage lean mass compared with lean men ( $\mathrm{p}<0.001$ for all) (Table 1). Girth measurements were also higher in overweight/obese men with a $19 \%$ larger waist circumference ( $p$ $<0.001)$, a $10 \%$ larger hip circumference $(\mathrm{p}<0.001)$ and a $10 \%$ larger waist-to-hip ratio $(\mathrm{p}<0.001)$ compared with lean men.

\section{Total energy and macronutrient intake}

Lean and overweight/obese men consumed similar amounts of total energy, protein, carbohydrate and fat (Table 2). There were no significant differences between the groups in these parameters. Overall (both groups combined), the meal

Table 1 Mean ( \pm SEM) baseline descriptive characteristics in lean and overweight/obese men

\begin{tabular}{llll}
\hline & $\begin{array}{l}\text { Lean } \\
(\mathbf{n = 1 9 )}\end{array}$ & $\begin{array}{l}\text { Overweight/Obese } \\
(\mathbf{n}=\mathbf{1 7})\end{array}$ & p value* \\
\hline Age (years) & $63.3 \pm 1.1$ & $61.1 \pm 1.1$ & 0.166 \\
Height $(\mathrm{cm})$ & $172.0 \pm 1.4$ & $174.8 \pm 1.4$ & 0.179 \\
Weight $(\mathrm{kg})$ & $69.7 \pm 1.6$ & $93.8 \pm 2.3$ & $<0.001$ \\
BMI $\left(\mathrm{kg} / \mathrm{m}^{2}\right)$ & $23.5 \pm 0.3$ & $30.6 \pm 0.6$ & $<0.001$ \\
\% Fat & $20.2 \pm 1.1$ & $28.1 \pm 0.9$ & $<0.001$ \\
\% Lean & $79.3 \pm 1.1$ & $72.0 \pm 0.9$ & $<0.001$ \\
Waist circumference $(\mathrm{cm})$ & $86.1 \pm 1.5$ & $106.9 \pm 1.5$ & $<0.001$ \\
Hip circumference $(\mathrm{cm})$ & $97.5 \pm 1.2$ & $109.2 \pm 1.3$ & $<0.001$ \\
WHR & $0.88 \pm 0.01$ & $0.98 \pm 0.01$ & $<0.001$ \\
\hline
\end{tabular}

*Univariate analysis of variance.

$B M I$ body mass index, \% Fat percentage body fat, \% Lean percentage lean mass, WHR waist to hip ratio.
Table 2 Mean ( \pm SEM) total energy and macronutrients consumed by lean and overweight/obese men

\begin{tabular}{llll}
\hline & $\begin{array}{l}\text { Lean } \\
(\mathbf{n}=\mathbf{1 9})\end{array}$ & $\begin{array}{l}\text { Overweight/Obese } \\
(\mathbf{n = 1 7 )}\end{array}$ & p value* \\
\hline Total energy (kJ) & $2895 \pm 245$ & $3015 \pm 235$ & 0.728 \\
Protein (g) & $27.2 \pm 2.1$ & $29.9 \pm 2.5$ & 0.396 \\
Carbohydrate (g) & $65.2 \pm 6.4$ & $73.0 \pm 5.4$ & 0.362 \\
Fat (g) & $37.2 \pm 4.3$ & $35.7 \pm 4.3$ & 0.801 \\
\hline
\end{tabular}

*Univariate analysis of variance.

consumed by the participants consisted of $22 \%$ protein, $53 \%$ carbohydrates and $25 \%$ fat.

\section{Salivary cortisol}

Saliva concentrations of cortisol in lean and overweight/ obese men are shown in Figure 1 and Table 3. In response to lunch, saliva concentrations of cortisol differed significantly between lean and overweight/obese men (time"treatment, $\mathrm{p}=0.008$; Figure 1). Further, separate analysis of the groups revealed a significant effect of time in overweight/obese men $(\mathrm{p}=0.005)$ but not in lean men $(p=0.384)$. The peak height of cortisol concentrations in the overweight/obese group $(0.654 \pm 0.09 \mu \mathrm{g} / \mathrm{dL})$ was significantly higher than pre-treatment concentrations $(0.345 \pm 0.03 \mu \mathrm{g} / \mathrm{dL})(\mathrm{p}=0.003)$. This corresponded to an $86 \%$ increase in cortisol concentrations from pretreatment concentrations to the peak height of the response in overweight/obese men. There were no significant differences between the groups in peak height for the cortisol response (Table 3). Area under the curve for cortisol was significantly higher in the overweight/obese men compared with lean men $(\mathrm{p}=0.039)$ and there was

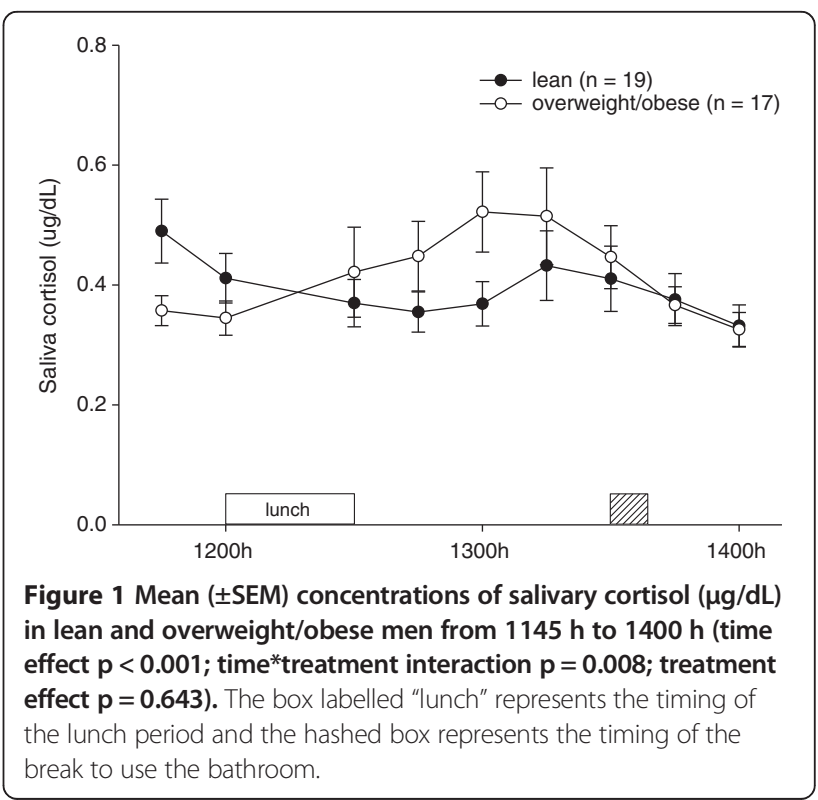


Table 3 Mean $( \pm$ SEM) pre-treatment salivary cortisol, peak height of salivary cortisol, salivary cortisol reactivity and area under the curve for lean and overweight/obese men

\begin{tabular}{llll}
\hline & $\begin{array}{l}\text { Lean } \\
(\mathbf{n}=19)\end{array}$ & $\begin{array}{l}\text { Overweight/Obese } \\
(\mathbf{n}=\mathbf{1 7})\end{array}$ & p value* \\
\hline Pre-treatment $(\mu \mathrm{g} / \mathrm{dL})$ & $0.411 \pm 0.04$ & $0.345 \pm 0.03$ & 0.204 \\
Peak height $(\mu \mathrm{g} / \mathrm{dL})$ & $0.532 \pm 0.06$ & $0.654 \pm 0.09$ & 0.251 \\
Reactivity $(\mu \mathrm{g} / \mathrm{dL})$ & $0.121 \pm 0.06$ & $0.309 \pm 0.08$ & 0.083 \\
AUC $\left(\mu \mathrm{g}^{*} \mathrm{~min} / \mathrm{dL}\right)$ & $-3.250 \pm 19.49$ & $10.182 \pm 18.03$ & 0.039
\end{tabular}

* Univariate analysis of variance.

AUC Area under the curve.

a trend towards cortisol reactivity being higher in overweight/obese men compared with lean men $(p=0.083$; Table 3). Repeated measures analysis of variance revealed that there was a significant overall effect of time $(\mathrm{p}<0.001$; Figure 1). There was no significant between subjects effect indicating that there were no significant overall differences between the groups $(\mathrm{p}=0.643)$.

\section{Salivary alpha amylase}

Saliva concentrations of alpha amylase in lean and overweight/obese men are shown in Figure 2 and Table 4. Repeated measures analysis of variance revealed that there was a significant effect of time $(\mathrm{p}<0.001$; Figure 2$)$. Overall (both groups combined), the peak height of salivary alpha amylase concentrations $(235 \pm 24.6 \mu \mathrm{g} / \mathrm{dL})$ was significantly higher than pre-treatment concentrations $(131 \pm 12.8 \mu \mathrm{g} / \mathrm{dL})(\mathrm{p}<0.001)$. Overall, there was an $80 \%$ increase in salivary alpha amylase concentrations from pre-treatment concentrations to the peak of the response (both groups combined).

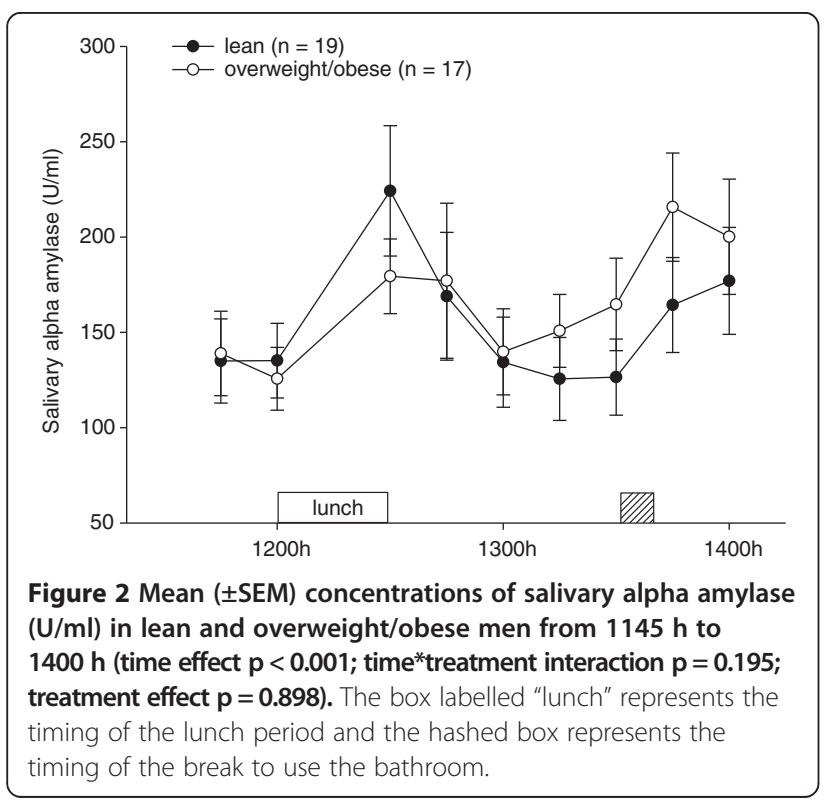

Table 4 Mean ( \pm SEM) pre-treatment salivary alpha amylase, peak height of salivary alpha amylase, salivary alpha amylase reactivity and area under the curve for lean and overweight/obese men

\begin{tabular}{llll}
\hline & $\begin{array}{l}\text { Lean } \\
(\mathbf{n = 1 9 )}\end{array}$ & $\begin{array}{l}\text { Overweight/Obese } \\
(\mathbf{n}=\mathbf{1 7})\end{array}$ & p value* \\
\hline Pre-treatment $(\mathrm{U} / \mathrm{ml})$ & $135 \pm 19.6$ & $126 \pm 16.5$ & 0.716 \\
Peak height $(\mathrm{U} / \mathrm{ml})$ & $228 \pm 33.7$ & $242 \pm 37.1$ & 0.771 \\
Reactivity $(\mathrm{U} / \mathrm{ml})$ & $93 \pm 25.0$ & $117 \pm 26.4$ & 0.510 \\
AUC $\left(\mathrm{U}^{*} \mathrm{~min} / \mathrm{ml}\right)$ & $2288 \pm 1427$ & $2863 \pm 4254$ & 0.751 \\
\hline
\end{tabular}

*Univariate Analysis of Variance.

AUC Area under the curve.

Saliva concentrations of alpha amylase in response to the lunch did not differ significantly between lean and overweight/obese men (time treatment, $\mathrm{p}=0.195$; Figure 2) and accordingly, there were no significant differences between the groups in peak height, reactivity or area under the curve for the salivary alpha amylase response (Table 4). There was no significant between subjects effect $(\mathrm{p}=0.898)$ indicating that there were no significant overall differences between the groups.

\section{Cardiovascular parameters}

Cardiovascular parameters in lean and overweight/obese men are shown in Figure 3 and Table 5.

\section{Systolic blood pressure}

There was a significant effect of time for systolic blood pressure ( $\mathrm{p}=0.001$; Figure $3 \mathrm{a})$. Overall (both groups combined), the peak height of systolic blood pressure (129 \pm $3 \mathrm{mmHg}$ ) was significantly higher than pre-treatment systolic blood pressure $(124 \pm 3 \mathrm{mmHg})(\mathrm{p}=0.03)$.

Systolic blood pressure in response to the lunch did not differ significantly between lean and overweight/ obese men (time*treatment, $\mathrm{p}=0.726$; Figure 3a). Systolic blood pressure reactivity and area under the curve did not differ between the two groups (Table 5). However, overweight/obese men had significantly higher pretreatment and peak height values for systolic blood pressure compared with the lean men ( $\mathrm{p}<0.05$ for both; Table 5). There was also a trend towards systolic blood pressure being significantly higher overall in the overweight/obese men compared with the lean men (between subjects effect, $\mathrm{p}=0.058$ ).

\section{Diastolic blood pressure}

Repeated measures analysis of variance revealed that there was a significant effect of time for diastolic blood pressure $(\mathrm{p}<0.001$; Figure $3 \mathrm{~b})$. Overall (both groups combined), the peak height of diastolic blood pressure $(74 \pm 2 \mathrm{mmHg})$ was significantly higher than pre-treatment diastolic blood pressure $(71 \pm 2 \mathrm{mmHg})(\mathrm{p}=0.03)$. 
Figure 3 Mean $( \pm$ SEM) a) systolic blood pressure $(\mathrm{mmHg})$, b) diastolic blood pressure $(\mathrm{mmHg}), \mathrm{c}$ ) mean arterial pressure $(\mathrm{mmHg})$ and d) heart rate $(\mathrm{bpm})$ in lean and overweight/obese men from $1145 \mathrm{~h}$ to $1400 \mathrm{~h}$ (time effect $\mathrm{p}=0.001,0.000,0.007$, 0.087 , respectively; time ${ }^{*}$ treatment interaction $p=0.726,0.898$, $0.713,0.620$, respectively; treatment effect $p=0.058,0.022$, $\mathbf{0 . 0 2 6}, \mathbf{0 . 7 0 9}$, respectively). The boxes labelled "lunch" represent the timing of the lunch period and the hashed boxes represent the timing of the break to use the bathroom.

Diastolic blood pressure in response to the lunch did not differ significantly between lean and overweight/ obese men (time*treatment, $\mathrm{p}=0.898$; Figure $3 \mathrm{~b}$ ). This finding was consistent with a lack of significant difference in reactivity and area under the curve of diastolic blood pressure between lean and overweight/obese men (Table 5). Nevertheless, overweight/obese men had a significantly higher pre-treatment diastolic blood pressure and peak height compared with the lean men (Table 5). There was a significant between subjects effect indicating that the overweight/obese men had higher diastolic blood pressure overall than the lean men $(\mathrm{p}=0.022)$.

\section{Mean arterial pressure}

There was a significant effect of time for mean arterial pressure $(\mathrm{p}=0.007$; Figure $3 \mathrm{c}$ ). Overall (both groups
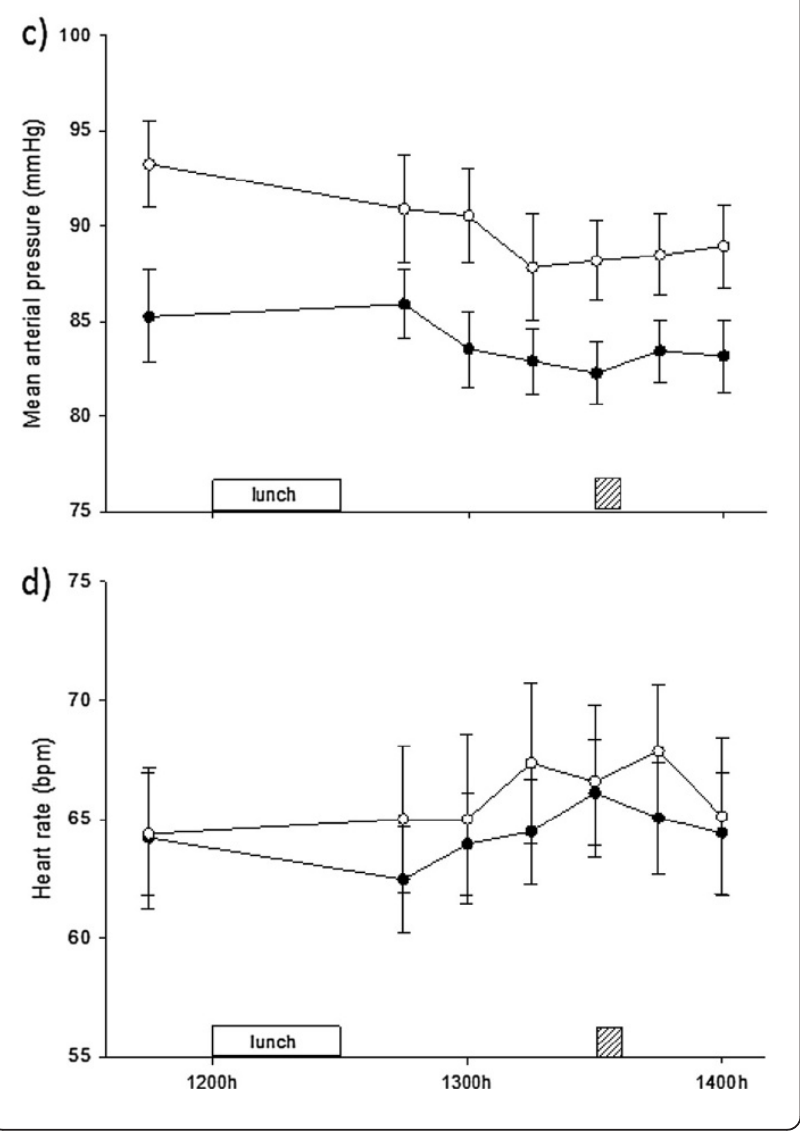

Table 5 Mean ( \pm SEM) pre-treatment, peak height, reactivity and area under the curve for SBP, DBP, MAP and HR in lean and overweight/obese men

\begin{tabular}{lllll}
\hline SBP & Pre-treatment $(\mathrm{mmHg})$ & $\begin{array}{l}\text { Lean } \\
(\mathbf{n}=\mathbf{1 9})\end{array}$ & $\begin{array}{l}\text { Overweight/ } \\
\text { Obese } \\
(\mathbf{n}=\mathbf{1 7})\end{array}$ & p value* \\
& Peak height $(\mathrm{mmHg})$ & $125 \pm 3$ & $129 \pm 3$ & 0.030 \\
& Reactivity $(\mathrm{mmHg})$ & $6 \pm 2$ & $5 \pm 3$ & 0.046 \\
& AUC (mmHg*min) & $-173 \pm 143$ & $-19 \pm 178$ & 0.820 \\
DBP & Pre-treatment (mmHg) & $68 \pm 2$ & $75 \pm 2$ & 0.027 \\
& Peak height (mmHg) & $71 \pm 1$ & $76 \pm 3$ & 0.017 \\
& Reactivity (mmHg) & $3 \pm 2$ & $3 \pm 2$ & 0.956 \\
& AUC (mmHg*min) & $-15 \pm 108$ & $33 \pm 131$ & 0.780 \\
MAP & Pre-treatment (mmHg) & $85 \pm 2$ & $93 \pm 2$ & 0.022 \\
& Peak height (mmHg) & $89 \pm 1$ & $95 \pm 2$ & 0.026 \\
& Reactivity (mmHg) & $3 \pm 2$ & $2 \pm 2$ & 0.588 \\
& AUC (mmHg*min) & $55 \pm 118$ & $254 \pm 142$ & 0.289 \\
HR & Pre-treatment (bpm) & $64 \pm 3$ & $64 \pm 3$ & 0.968 \\
& Peak height (bpm) & $67 \pm 2$ & $69 \pm 3$ & 0.628 \\
& Reactivity (bpm) & $3 \pm 2$ & $5 \pm 1$ & 0.483 \\
AUC (bpm*min) & $56 \pm 134$ & $-109 \pm 99$ & 0.337 \\
\hline
\end{tabular}

*Univariate Analysis of Variance.

SBP Systolic blood pressure, DBP Diastolic blood pressure, MAP Mean arterial pressure, $H R$ Heart rate, AUC Area under the curve. 
combined), there was a trend towards the peak height of mean arterial pressure $(92 \pm 2 \mathrm{mmHg})$ being significantly higher than pre-treatment $(89 \pm 2 \mathrm{mmHg})(\mathrm{p}=0.06)$.

Mean arterial pressure in response to the lunch did not differ significantly between lean and overweight/ obese men (time*treatment, $\mathrm{p}=0.713$; Figure 3c). Mean arterial pressure reactivity and area under the curve were similar in overweight/obese men compared with lean men (Table 5). Overweight/obese men had a significantly higher pre-treatment and peak height for mean arterial pressure compared with lean men (Table 5). There was also a significant between subjects effect indicating that the overweight/obese men had higher mean arterial pressure overall compared with lean men $(\mathrm{p}=0.026)$.

\section{Heart rate}

There was no significant effect of time for heart rate $(\mathrm{p}=0.087$; Figure $3 \mathrm{~d})$. Overall (both groups combined), the peak height of heart rate $(68 \pm 3 \mathrm{bpm})$ was not significantly different to pre-treatment heart rate $(64 \pm$ $3 \mathrm{bpm})(\mathrm{p}=0.16)$.

Heart rate following lunch did not differ significantly between lean and overweight/obese men (time"treatment, $\mathrm{p}=0.620$; Figure $3 \mathrm{~d}$ ) and accordingly, there were no significant differences between the groups in peak height, heart rate reactivity or area under the curve for heart rate (Table 5). There were also no significant differences between the groups in pre-treatment heart rate (Table 5) and there was no significant overall between subjects effect indicating that there were no significant overall differences between the groups for heart rate $(\mathrm{p}=0.709)$.

\section{Discussion}

Our hypothesis that overweight/obese men will have greater cortisol and alpha amylase responses to the challenge of food consumption compared with lean men was partially supported. Overweight/obese men showed a greater activation of the HPA axis to food intake compared with lean men as indicated by the higher response of salivary cortisol. Contrary to our hypothesis, both groups showed a similar salivary alpha amylase response to consumption of food. Systolic blood pressure, diastolic blood pressure, mean arterial pressure and heart rate responses were also similar between the groups in response to lunch indicating that there is no difference in SAM system activation in response to food intake between lean and overweight/obese men.

The finding that only overweight/obese men showed a significant HPA axis response to food intake is of particular importance. This is in accord with the findings of Vicennati and colleagues in women with abdominally distributed body fat (waist to hip ratio $>0.85$ ) in response to the ingestion of a high carbohydrate meal [13].
Nevertheless, it should be noted that the meal used by Vicennati et al. contained $89 \%$ carbohydrates whereas ours only contained 53\% carbohydrates. This suggests that even moderate levels of carbohydrates can elicit a significant HPA axis response in overweight/obese men. The notion that even moderate levels of carbohydrates can elicit significant HPA axis activity is of particular significance, especially in the context of the modern day western diets including large quantities of refined carbohydrates [25]. This could even be more relevant to individuals who are already overweight/obese and are on a high carbohydrate diet because regular elevations of cortisol may further complicate metabolic anomalies that may already exist. Findings by Martens et al. further reiterate the importance of the carbohydrate content in eliciting cortisol responses to food intake [14]. They reported that protein or fat intake can decrease cortisol responses, whereas ingestion of carbohydrates increased cortisol responses. Therefore, it appears that the carbohydrate content of a meal can play a significant role in activating the HPA axis.

Lean men did not show a significant elevation in cortisol after consumption of the standardised lunch in the current experiment. This is contrary to the findings of Gibson and colleagues in 1999 where they investigated cortisol responses to a high protein (39\%) lunch in healthy men [12]. It should be noted that the contribution of protein towards the total energy in the current experiment was only $22 \%$. Therefore, it appears that a protein content as low as $22 \%$ can elicit significant HPA axis response in overweight/obese men. This also suggests that a significant HPA axis response is dependent on a higher protein content only in lean men. The energy intake in the current study is also similar to that of the average Australian energy intake for men (22\% protein, $45 \%$ carbohydrate and $32 \%$ fat) as reported in the 1995 National Nutrition Survey [26]. Therefore, it is highly likely that overweight/obese men will consume a diet that can elicit a significant cortisol response every time they eat.

Abdominal obesity can be associated with disrupted endocrine as well as neural feedback from the brain-gut axis to the HPA axis [27]. Food can stimulate the secretion of certain peptides/hormones such as insulin, leptin, ghrelin, cholecystokinin, and pancreatic peptide $\mathrm{Y}$ which can in turn have an impact on the HPA axis activity $[28,29]$. It has been reported that these feedback pathways are malfunctioning in obese individuals [30]. Overweight/obese men in the current study had significantly higher waist to hip ratios compared with the lean men suggesting that they had a higher proportion of abdominally distributed fat. Therefore, it is possible that abdominally based body fat distribution in the overweight/ obese men may have contributed towards the higher 
HPA axis response to the lunch. There are several mechanisms that may play a role in overweight/obese individuals having a higher cortisol response to food intake. For example, differences in stimulation of the HPA axis compared with lean individuals, perhaps through increased noradrenergic drive, decreased negative feedback and/or increased corticotrophin releasing hormone and arginine vasopressin synthesis and secretion are plausible mechanisms for the pattern of results observed [31]. Cortisol plays a major role in metabolism [32] and it is well known that variations in cortisol can have a significant impact on nutrient absorption [33,34]. Cortisol contributes towards lipolysis and proteolysis thus it increases the plasma free fatty acid availability. This could potentially accentuate the deposition of abdominal fat or further complicate existing manifestations of obesity. Furthermore, hyperactivity of the HPA axis has been shown to be associated with cardiovascular disease [35], type 2 diabetes [36] and anxiety and depression [37].

None of the previous studies in this area has investigated the effects of food consumption on the activity of the SAM system in lean and overweight/obese men. Our results indicate that, with the exception of heart rate, all of the SAM system parameters that were measured in the current experiment (salivary alpha amylase, systolic blood pressure, diastolic blood pressure and mean arterial pressure) increased in response to lunch (time effect for all parameters $\mathrm{p}<0.05$ ). These findings partially concur with the reports of Harthoorn et al. who found increases in sympathetic nervous system activity after ingestion of a standardised meal (15-20\% protein, 35-40\% fat and $40-45 \%$ carbohydrate) in a group of healthy men and women [38]. Increases in sympathetic nervous system activity are to be expected as eating places a demand on the cardiovascular system. It has been reported that the postprandial increase in heart rate together with the subsequent increase in cardiac output facilitates the rise in demand for blood flow to the visceral areas [39]. However, there was no such effect on heart rate in the current experiment. The reduction in systolic blood pressure, diastolic blood pressure and mean arterial pressure in the postprandial period (i.e., $1245 \mathrm{~h}-1330 \mathrm{~h}$ in the current experiment) may be a result of the reduction in resistance to blood flow in the mesenteric vessels. Another plausible explanation could be that the satiety hormones are having an inhibitory effect on the sympathetic nervous system during this period $[40,41]$. These findings suggest that there is no differential SAM system response to food intake in men based on the level of adiposity.

It has previously been reported that sympathetic nervous system response to food intake can be bi-phasic in nature [38]. Harthoorn et al. reported a secondary increase in sympathetic nervous system activity about $45-50$ minutes post ingestion of a meal. This could be attributed to the physiological changes that happen due to the gastrointestinal mechanisms of digestion of food. While this previously reported increase is somewhat similar to the secondary rise in salivary alpha amylase and blood pressure parameters in the current experiment, the increase in the current experiment occurred with a greater delay (75-90 minutes) after the ingestion of the meal. The secondary increase in our experiment coincided with the bathroom break that was offered to participants after the $1330 \mathrm{~h}$ sample collection. Consequently, it is not possible to determine in the current experiment if this secondary increase in SAM system activity is a result of gastrointestinal mechanisms of food ingestion or merely an artefact of the participants physically moving during the bathroom break.

The current experiment is the first of its kind to investigate both SAM system and HPA axis responses simultaneously in response to food intake. While the measurement of saliva cortisol (which is in a high concentration per volume range; ug/dl range) has been shown to be unaffected by blood contamination due to micro-injury of the oral cavity [23], blood contamination has been shown to influence the measurement of steroid hormones present in the very low concentration per volume range ( $\mathrm{pg} / \mathrm{ml}$ range) including salivary testosterone [23], salivary oestradiol [42] and salivary progesterone [42]. Therefore, to support the outcomes of the current study, future research could confirm these findings in a similarly designed study that measures plasma cortisol instead of salivary cortisol. Future experiments could also consider females and participants of different age groups.

\section{Conclusions}

In conclusion, this experiment showed that increased adiposity in men was associated with hyperactivity of the HPA axis after the ingestion of a meal consisting of $22 \%$ protein, $53 \%$ carbohydrates and $25 \%$ fat. This suggests that ingesting a standardised meal can result in differential HPA axis but not SAM system activation in overweight/obese men of 50-70 years compared with age matched lean men.

\section{Competing interests}

This research was funded by Deakin University. The authors declare that they have no competing interests.

\section{Authors' contributions}

SUJ, AIT and SJT designed the experiment, managed recruitment and undertook data collection. Bio chemical and cardiovascular analyses were conducted by SUJ under the guidance of AIT, SJT and CAN. AJT made substantial contributions to the analysis and interpretation of data. All authors made substantial contributions in revising the manuscript and approval of the final version.

\section{Acknowledgements}

The authors thank John Reynolds for advice about statistical and power analyses, Emma Townsin, Sara Drew and Maryam Delavari for technical support and all of the participants for being involved in this research. 


\section{Author details}

${ }^{1}$ Centre for Physical Activity and Nutrition Research, School of Exercise and Nutrition Sciences, Deakin University, Burwood VIC 3125, Australia. 'Livestock and Farming Systems, South Australian Research and Development Institute, University of Adelaide, Roseworthy SA 5371, Australia.

Received: 27 February 2014 Accepted: 23 July 2014

Published: 15 August 2014

\section{References}

1. Elenkov IJ, Chrousos GP: Stress hormones, proinflammatory and antiinflammatory cytokines, and autoimmunity. Neuroendocrine Immune Basis Rheum Dis li, Proc 2002, 966:290-303. PubMed PMID: WOS:000177157700035.

2. Chrousos GP: Stress and disorders of the stress system. Nat Rev Endocrinol 2009, 5(7):374-381. PubMed PMID: WOS:000267204800007.

3. Roth J, Qiang XL, Marban SL, Redelt H, Lowell BC: The obesity pandemic: where have we been and where are we going? Obes Res 2004, 12:88. 2005 Mar;13(3). PubMed PMID: WOS:000228625500001.

4. Tilbrook AJ, Rivalland EAT, Turner Al, Lambert GW, Clarke IJ: Responses of the hypothalamopituitary adrenal axis and the sympathoadrenal system to isolation/restraint stress in sheep of different adiposity. Neuroendocrinology 2008, 87(4):193-205. PubMed PMID: WOS:000256407500001

5. Levin BE, Triscari J, Sullivan AC: Abnormal sympatho-adrenal function and plasma-catecholamines in obese zucker rats. Pharmacol Biochem Behav 1980, 13(1):107-113. PubMed PMID: WOS:A1980KC93300019.

6. Waldstein SR, Burns HO, Toth MJ, Poehlman ET: Cardiovascular reactivity and central adiposity in older African Americans. Health Psychol 1999, 18(3):221-228. PubMed PMID: WOS:000080418700003.

7. Pasquali R, Anconetani B, Chattat R, Biscotti M, Spinucci G, Casimirri F, Vicennati V, Carcello A, Labate AMM: Hypothalamic-pituitary-adrenal axis activity and its relationship to the autonomic nervous system in women with visceral and subcutaneous obesity: Effects of the corticotropin-releasing factor arginine-vasopressin test and of stress. Metab-Clinical Exp 1996, 45(3):351-356. PubMed PMID: WOS:A1996UA27600012.

8. Barnes VA, Treiber FA, Davis H, Kelley TR, Strong WB: Central adiposity and hemodynamic functioning at rest and during stress in adolescents. Int J Obes 1998, 22(11):1079-1083. PubMed PMID: WOS:000076625300007.

9. Reims HM, Fossum E, Hoieggen A, Moan A, Eide I, Kjeldsen SE: Adrenal medullary overactivity in lean, borderline hypertensive young men. Am J Hypertens 2004, 17(7):611-618. PubMed PMID: WOS:000222467100010.

10. Jern S, Bergbrant A, Bjorntorp P, Hansson L: Relation of central hemodynamics to obesity and body-fat distribution. Hypertension 1992, 19(6):520-527. PubMed PMID: WOS:A1992HX02200003.

11. Therrien F, Drapeau V, Lalonde J, Lupien SJ, Beaulieu S, Dore J, Tremblay A Richard D: Cortisol response to the Trier Social Stress Test in obese and reduced obese individuals. Biol Psychol 2010, 84(2):325-329. PubMed PMID: WOS:000279197500020

12. Gibson EL, Checkley S, Papadopoulos A, Poon L, Daley S, Wardle J: Increased salivary cortisol reliably induced by a protein-rich midday meal. Psychosom Med 1999, 61(2):214-224. PubMed PMID: WOS:000079301000014.

13. Vicennati V, Ceroni L, Gagliardi L, Gambineri A, Pasquali R: Response of the hypothalamic-pituitary-adrenocortical axis to high-protein/fat and high-carbohydrate meals in women with different obesity phenotypes. J Clinical Endocr Metab 2002, 87(8):3984-3988. PubMed PMID: WOS:000177285400073

14. Martens MJI, Rutters F, Lemmens SGT, Born JM, Westerterp-Plantenga MS: Effects of single macronutrients on serum cortisol concentrations in normal weight men. Physiol Behav 2010, 101(5):563-567. PubMed PMID: WOS:000285126300003

15. Nater UM, Rohleder N: Salivary alpha-amylase as a non-invasive biomarker for the sympathetic nervous system: Current state of research. Psychoneuroendocrinology 2009, 34(4):486-496. PubMed PMID: WOS:000265366200002

16. Ali N, Pruessner JC: The salivary alpha amylase over cortisol ratio as a marker to assess dysregulations of the stress systems. Physiol Behav 2012, 106(1):65-72. PubMed PMID: CCC:000301910000010. English.

17. Chatterton RT, Vogelsong KM, Lu YC, Ellman AB, Hudgens GA: Salivary alpha-amylase as a measure of endogenous adrenergic activity. Clin Physiol 1996, 16(4):433-448. PubMed PMID: WOS:A1996UY14300010.
18. Rohleder N, Wolf JM, Maldonado EF, Kirschbaum C: The psychosocial stress-induced increase in salivary alpha-amylase is. Psychophysiology 2006, 43(6):645-652. PubMed PMID: WOS:000241626200015

19. Rohleder N, Nater UM, Wolf JM, Ehlert U, Kirschbaum C: Psychosocial stress-induced activation of salivary alpha-amylase: an indicator of sympathetic activity? Ann N Y Acad Sci 2004, 1032(1):258-263.

20. Turner Al, Keating CL, Tilbrook AJ: Sex Differences and the Role of Sex Steroids in Sympatho-Adrenal Medullary System and Hypothalamo-Pituitary Adrenal Axis Responses to Stress. Sex steroids Rijeka, Croatia: InTech; 2012:115-136.

21. Tilbrook AJ: Neuropeptides, stress related. In Encylopedia of stress. 2(2)th edition. Amsterdam: Elsilver; 2007:903-908.

22. Dettwyler K, Lohman TG, Roche AF, Martorell R: Anthropometric Standardization Reference Manual, Abridged Edition American Journal of Physical Anthropology. 1993, 92(2):239-241. PubMed PMID: WOS: A1993LZ34600013.

23. Kivlighan KT, Granger DA, Schwartz EB, Nelson V, Curran M, Shirtcliff EA: Quantifying blood leakage into the oral mucosa and its effects on the measurement of cortisol, dehydroepiandrosterone, and testosterone in saliva. Horm Behav 2004, 46(1):39-46. PubMed PMID: WOS:000222517100005

24. Lemmens SG, Born JM, Martens EA, Martens MJ, Westerterp-Plantenga MS: Influence of consumption of a high-protein vs. high-carbohydrate meal on the physiological cortisol and psychological mood response in men and women. Plos One 2011, 6(2). PubMed PMID: WOS:000287036600030. English.

25. Bengmark S: Nutrition of the critically III-A 21st-century perspective. Nutrients 2013, 5(1):162-207. PubMed PMID: WOS:000314026700010.

26. McLennan W: National nutrition survey: nutrient intakes and physical measurements. Aust Bur Stat 1995, 4805.0:20-83.

27. Hussain SS, Bloom SR: The regulation of food intake by the gut-brain axis: implications for obesity. Int J Obes 2013, 37(5):625-633. PubMed PMID: WOS:000318772400001

28. Ishizuka B, Quigley ME, Yen SSC: Pituitary-hormone release in response to food ingestion - evidence for neuroendocrine signals from gut to brain. J Clin Endocrinol Metab 1983, 57(6):1111-1116. PubMed PMID: WOS:A1983RQ78000004.

29. Schwartz MW, Woods SC, Porte D, Seeley RJ, Baskin DG: Central nervous system control of food intake. Nature 2000, 404(6778):661-671. PubMed PMID: WOS:000086400100066.

30. Velloso LA, Schwartz MW: Altered hypothalamic function in diet-induced obesity. Int J Obes 2011, 35(12):1455-1465. PubMed PMID: WOS:000298414500001

31. Tilbrook AJ, Clarke IJ: Neuroendocrine mechanisms of innate states of attenuated responsiveness of the hypothalamo-pituitary adrenal axis to stress. Front Neuroendocrinol 2006, 27(3):285-307. PubMed PMID: WOS:000241760800003

32. Tempel DL, Leibowitz S: Adrenal-steroid receptors - interactions with brain neuropeptide systems in relation to nutrient intake and metabolism. J Neuroendocrinol 1994, 6(5):479-501. PubMed PMID: WOS: A1994PM05200002.

33. Simmons PS, Miles JM, Gerich JE, Haymond MW: Increased proteolysis - an effect of increases in plasma-cortisol within the physiologic range. J Clin Investig 1984, 73(2):412-420. PubMed PMID: WOS:A1984SD74800016.

34. Divertie GD, Jensen MD, Miles JM: Stimulation of lipolysis in humans by physiological hypercortisolemia. Diabetes 1991, 40(10):1228-1232. PubMed PMID: WOS:A1991GG60800002

35. Seldenrijk A, Hamer M, Lahiri A, Penninx BWJH, Steptoe A: Psychological distress, cortisol stress response and subclinical coronary calcification. Psychoneuroendocrinology 2012, 37(1):48-55. PubMed PMID: WOS:000298779200005

36. Steptoe A, Brydon L: Associations between acute lipid stress responses and fasting lipid levels 3 years later. Health Psychol 2005, 24(6):601-607. PubMed PMID: WOS:000233453600008.

37. Yoon $\mathrm{KL}$, Joormann J: Stress reactivity in social anxiety disorder with and without comorbid depression. J Abnorm Psychol 2012, 121(1):250-255. PubMed PMID: WOS:000300198500025.

38. Harthoorn LF, DransWeld E: Periprandial changes of the sympatheticparasympathetic balance related to perceived satiety in humans. Eur J Appl Physiol 2008, 102(5):601-608. PubMed PMID: WOS:000252540300014.

39. Jager K, Bollinger A, Valli C, Ammann R: Measurement of mesenteric blood-flow by duplex scanning. J Vasc Surg 1986, 3(3):462-469. PubMed PMID: WOS:A1986A407100009. 
40. Burcelin $\mathrm{R}$ : The incretins: a link between nutrients and well-being. $\mathrm{Br} J$ Nutr 2005, 93:S147-S156. PubMed PMID: WOS:000229006500019.

41. Fan W, Ellacott KLJ, Halatchev IG, Takahashi K, Yu PX, Cone RD:

Cholecystokinin-mediated suppression of feeding involves the brainstem melanocortin system. Nat Neurosci 2004, 7(4):335-336. PubMed PMID: WOS:000220482500009.

42. Kivlighan KT, Granger DA, Schwartz EB: Blood contamination and the measurement of salivary progesterone and estradiol. Horm Behav 2005, 47(3):367-370. PubMed PMID: WOS:000227326100017.

doi:10.1186/s40608-014-0014-4

Cite this article as: Jayasinghe et al: Cortisol, alpha amylase, blood

pressure and heart rate responses to food intake in men aged 50-70 years: importance of adiposity. BMC Obesity 2014 1:14.

\section{Submit your next manuscript to BioMed Central and take full advantage of:}

- Convenient online submission

- Thorough peer review

- No space constraints or color figure charges

- Immediate publication on acceptance

- Inclusion in PubMed, CAS, Scopus and Google Scholar

- Research which is freely available for redistribution 